\title{
パラメータ領域を利用した適応二次安定化制御系の構成*1 Synthesis of Adaptive Quadratic Control Systems Using Parameter Region
}

\author{
太田裕 文*2 \\ Hirobumi Ohta, Koji Yamanaka \\ 松 岡 美 和 ${ }^{* 4}$ \\ and Miwa Matsuoka
}

Key Words : Adaptive Control, Flight Control, Quadratic Stabilization, Parameter Region

\begin{abstract}
There still remain many problems to be solved for conventional adaptive control theory to be applied to a real plant. Some of them are restrictive conditions imposed on the plant, low robustness and poor transient properties. To overcome these problems, we present a new design method of adaptive controllers that are robust to plant noise and uncertainties and have a good transient property. We first propose an algorithm to evaluate and reduce the parameter region in which the transfer function of a real plant exists. According to these plant informations, we can judge how closely the identification is made towards real parameters and whether it is better to continue identification or to execute some control strategy. Stabilizability of the plant is determined by one Riccati equation so that the plant can be stabilized by a quadratic stabilization controller. Some numerical examples together with application to a flight controller design are given to illustrate and substantiate the effectiveness of the proposed method.
\end{abstract}

\section{1.はじめに}

適応制御とは、ナ゙ラントの特性変動に応じて制御系 を自動調整し，制御対象の性能をつねに良好に保つこ とを目的とした制御方式であり，航空機等の動作環境 の変化を伴う制御対象に有効である.航空機の飛行制 御系は, 離陸してから目的地に着陸するまで高度や速 度の大きく違った様々な環境におかれ，それに応じて 空力特性も大幅に変わる. 従って, 航空機の入出力情 報によって機体の動特性を推定し，その情報に基づい て制御系を構成していくという考えは極めて自然なも

*1 平成 4 年 11 月 18 日，第 9 回誘導制御シンポジウムで一部 発表. 平成 8 年 3 月 21 日原稿受理

$* 2$ 大阪府立大学工学部

*3 宇宙開発事業団

*4 名古屋大学大学院
のである.ところが現状の適応制御理論を航空機等へ 応用する場合, その過渡状態での入出力特性の問題が 大きな障害となる。それは適応制御系が，過渡状態に おいて実現不可能な入力ゃ不適切な出力を発生してし まうことである。

適応制御系は基本的に同定則やパラメータ調整則と 制御則の結合したものである。しかし本質的に非線形 であり，無限時間での収束性を基本に理論が構成され ているために，過渡特性に対する一般的な解析は困難 であり，扱っている論文も少ない。

代表的な適応制御則であるモデル規範形適応制御シ ステム(MRACS) は，モデルマッチングの特性を生か した方法であるが，プラントに課される制約条件が多 く，またたとえ信号の有界性が保証されたとしても， パラメータ調整則と制御則との相互干涉による入出力 変化を予め評価することは容易でない. Millerらの 過渡特性を考慮した MRACS は11，その論文中にも述 べられている通り，基本的にハイゲイン制御に基づい ており，実用上困難を伴うものである．

相互干涉の問題はパラメー夕調整と制御が同時に行 われることに起因する．その観点からも，パラメータ 同定則及び状態推定器 (もしくはそれらの機能を合わ せ持つ適応観測器) と何らかの制御則, 例えば極配置 や最適レギュレータを分離して利用すれば理論的見通 しが比較的容易になる. Samsonらの LQアプロー チ2) は非最小位相系にも用いることができる上，入出 力の重みをうまく選べば特性も比較的良好である。も っとも, 重みの選定と入出力特性の関係は, 初期值, 同定則の設定パラメー夕等も含めた強い非線形であ り，最適レギュレータのような定性的な性質は持ち得 ない.

本研究では現状の適応制御理論の問題点を踏まえ， 過渡特性を改善することを試みる。そのため一般の適 
応制御則が持つ同定則の他に，パラメータ存在領域を 逐次縮小する機構を設け，同定值の真值からのずれを 「誤差」として評価し，最近のロバスト制御理論との 融合を図る。

\section{2. パラメータ存在領域}

前述の通り，適応制御系の過渡特性を悪化させてい る最大の原因は，パラメータ調整則と制御則の相互干 涉である，適応制御とはそもそも未知なる系に対する 制御ではあるが，プラントの情報が「未知」である状 態で積極的な制御を行うことに意味があるとは考えに くい.しかし一方で，プラントの情報が十分に得られ るのをただ待つというのでも適応制御の有効性は発揮 されない. 結局, 各時間で, 同定值が真值に対してど れくらい「良好」なものであるかを何らかの形で評価 し，その情報に対して最も有効な制御則を決めること が必要である.

この評価の手法の一つとして「パラメータ存在領 域」の利用を考える，パラメータ存在領域とは，未知 パラメータからなる末知べクトル $\theta$ のそれぞれの要 素 $\theta_{i}$ が存在する領域 $\left[\theta_{i}^{\min }, \theta_{i}^{\max }\right]$ のことであり，空間 の中で $\theta$ を含む超直方体である，存在領域は，元々 適応制御系の可制御性を論じるために用いられ、同定 值がその領域内に含まれるように同定則を修正して利 用された3). 実際の制御対象を考えれば，各パラメー 夕は物理的に上下限を持っており, その意味で存在領 域を仮定することは自然である，そこで，初期パラメ 一夕存在領域を逐次縮小することにより，より正確な 末知パラメータの值を求めることができる。

存在領域の逐次縮小は，適応制御系のオーバーシュ 一トを防ぐアルゴリズムに利用するために，離散時間 系について考えられている4．ただしそのアルゴリズ 厶は最小二乗形同定則の特徵が取り入れられていない 為に収束が遅く，従ってプラントの情報が未獲得な状 態が長く続いてしまうことになる．前述したように， プラントの情報未知の場合，積極的な制御は行わない 方が合理的ではあるが，不安定なプラントに対してプ ラント末知の状態が長く続くことは望ましくない。 そ こで逐次宿小アルゴリズムは，i）入力が PE(Persistent Exciting) 条件9)を満たすならぱパラメータの 真値に向かって縮小されること，ii）振幅の小さい入 力に対しても縮小されること，iii）収束が速いことの 三つの特性を有すべきである.

\section{3. パラメータ存在領域縮小}

本節では上記の特性を備えたパラメー夕領域縮小ア ルゴリズムを，離散時間系及び連続時間系それぞれに
対して構成する。

3.1 離散時間系 対象とするシステムは入出力の 時系列モデルとして

$$
y(k)=-\sum_{j=1}^{n} a_{j} y(k-j)+\sum_{j=1}^{n} b_{j} u(k-j)
$$

のように書かれるとする，ここで $y(k)$ は出力， $u(k)$ は制御入力である。また， $a_{j}, b_{j}$ は未知であるので (1)式を

$$
y(k)=\zeta^{\mathrm{T}}(k-1) \theta
$$

と同定に便利な形に書き直す， $\theta$ は未知パラメータか

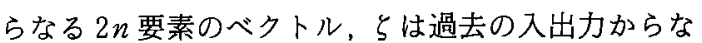
る $2 n$ 要素の回帰ベクトルで，それぞれ次のようにな る。

$$
\begin{aligned}
& \zeta(k-1)=[-y(k-1) \cdots-y(k-n) \\
& u(k-1) \cdots u(k-n)]^{\mathrm{T}} \\
& \theta=\left[\begin{array}{llllllll}
a_{1} & a_{2} & \cdots & a_{n} & b_{1} & b_{2} & \cdots & b_{n}
\end{array}\right]^{\mathrm{T}}
\end{aligned}
$$

以上のシステムに対し，パラメータ領域縮小のため のアルゴリズムを以下に与える，ただし以降の式に現 れる $\|A\|_{\infty}$ は

$$
\|A\|_{\infty} \equiv \max _{i} \sum_{j=1}^{n}\left|a_{i j}\right|
$$

と定義されるものとする.

《アルゴリズム $1 》$

1. 真值 $\theta$ の各要素 $\theta_{i}$ に対して, $\theta_{i}^{\max }(0)-\theta_{i} \geq 0$, $\theta_{i}^{\min }(0)-\theta_{i} \leq 0(i=1,2, \cdots, 2 n)$ となるような $\left[\theta_{i}^{\min }(0)\right.$, $\left.\theta_{i}^{\max }(0)\right]$ を評価する。

2. $\gamma=\frac{1}{2} \max _{i}\left(\theta_{i}^{\max }(0)-\theta_{i}^{\min }(0)\right)(i=1,2, \cdots, 2 n)$ と 极了。

3. 次の(指数重み付き)最小二乗同定則を用いて $\theta$ の推定值 $\hat{\theta}(k)$ を計算する.

$$
\begin{aligned}
\hat{\theta}(k)= & \hat{\theta}(k-1) \\
& -\frac{\Gamma(k-1) \zeta(k-1)\left[\zeta^{\mathrm{T}}(k-1) \hat{\theta}(k-1)-y(k)\right]}{\lambda+\zeta^{\mathrm{T}}(k-1) \Gamma(k-1) \zeta(k-1)} \\
\Gamma(k)= & \frac{1}{\lambda}[\Gamma(k-1) \\
& \left.-\frac{\Gamma(k-1) \zeta(k-1) \zeta^{\mathrm{T}}(k-1) \Gamma(k-1)}{\lambda+\zeta^{\mathrm{T}}(k-1) \Gamma(k-1) \zeta(k-1)}\right]
\end{aligned}
$$

$$
\Gamma(0)=\Gamma^{\mathrm{\tau}}(0)>0, \quad 0<\lambda \leq 1
$$

4. $\alpha(k)=\lambda^{k}\left\|\Gamma(k) \Gamma^{-1}(0)\right\|_{\infty} \gamma$ を計算する.

5. すると以上より, $k$ 時での $\theta_{i}$ の存在領域が

$\theta_{i}^{\min }(k)=\max \left[\theta_{i}^{\min }(k-1), \hat{\theta}_{i}(k)-\alpha(k)\right]$

$\theta_{i}^{\max }(k)=\min \left[\theta_{i}^{\max }(k-1), \hat{\theta}_{i}(k)+\alpha(k)\right]$

$$
(i=1,2, \cdots, 2 n)
$$

で与えられる。

アルゴリズム1で得られるパラメータ領域に関して 
次の定理が成り立つ.

[定理 1] アルゴリズム 1 で得られる $\theta_{i}^{\min }(k)$, $\theta_{i}^{\max }(k)(i=1, \cdots, 2 n)$ は以下の関係を満たす.

1. $\theta_{i}^{\min }(k) \leq \theta_{i} \leq \theta_{i}^{\max }(k) \quad \forall k$

2. $\theta_{i}^{\min }(k-1) \leq \theta_{i}^{\min }(k) \quad \forall k$ $\theta_{i}^{\max }(k-1) \geq \theta_{i}^{\max }(k) \quad \forall k$

3. ベクトル $(k)$ が $\mathrm{PE}$ 条件を満たし、 $\|\Gamma(k)\|_{\infty}$ が有界ならば， $\theta_{i}^{\min }(k), \theta_{i}^{\max }(k)$ は真值 $\theta_{i}$ に収束す る。

定理 1 を証明するために次の補題を利用する。

[補題 1] ベクトル $\zeta(k)$ が PEであり, $\|\Gamma(k)\|_{\infty}$ が 有界ならば, $\phi(k)=\hat{\theta}(k)-\theta$ に対して

$$
\|\psi(k)\|_{\infty} \leq \lambda^{k}\left\|\Gamma(k) \Gamma^{-1}(0)\right\|_{\infty} \gamma
$$

がすべての $k$ で成り立つ.

補題 1 は(指数重み付き)最小二乗形パラメータ同定 則のいわわる指数収束性を示す式であるが，以下での 議論のために文献 5)とは別の証明を与えておく。

(補題 1 の証明) (3)，(4)式より

$$
\begin{aligned}
& \Gamma(k) \zeta(k-1)=\frac{\Gamma(k-1) \zeta(k-1)}{\lambda+\zeta^{\mathrm{T}}(k-1) \Gamma(k-1) \zeta(k-1)} \\
& \psi(k)= \phi(k-1) \\
&-\Gamma(k) \zeta(k-1) \zeta^{\mathrm{T}}(k-1) \psi(k-1) \\
& \Gamma(k)= \frac{1}{\lambda}[\Gamma(k-1) \\
&\left.-\Gamma(k) \zeta(k-1) \zeta^{\mathrm{T}}(k-1) \Gamma(k-1)\right]
\end{aligned}
$$

となるので，

$$
\begin{aligned}
\psi(k)= & \psi(k-1) \\
& -\Gamma(k)\left\{\Gamma^{-1}(k)-\lambda \Gamma^{-1}(k-1)\right\} \psi(k-1) \\
= & \lambda \Gamma(k) \Gamma^{-1}(k-1) \psi(k-1) \\
= & \lambda^{k} \Gamma(k) \Gamma^{-1}(0) \psi(0)
\end{aligned}
$$

と与えられる。このノルムを評価すると

$$
\begin{aligned}
\|\psi(k)\|_{\infty} \leq \lambda^{k}\left\|\Gamma(k) \Gamma^{-1}(0)\right\|_{\infty}\|\psi(0)\|_{\infty} \\
\leq \lambda^{k}\left\|\Gamma(k) \Gamma^{-1}(0)\right\|_{\infty} \gamma
\end{aligned}
$$

が得られる。 \|

\section{(定理 1 の証明)}

1. 帰納法による。 $\theta_{i}^{\max }(k-1)-\theta_{i} \geq 0$ と仮定する $\varepsilon$,

$$
\begin{aligned}
& \theta_{i}^{\max }(k)-\theta_{i} \\
& \quad=\min \left[\theta_{i}^{\max }(k-1)-\theta_{i}, \hat{\theta}_{i}(k)+\alpha(k)-\theta_{i}\right]
\end{aligned}
$$

ここで補題 1 より $\alpha(k) \geq\|\bar{\theta}(k)-\theta\|_{\infty}$ であるから， $\theta_{i}^{\max }(k)-\theta_{i} \geq \min \left[\theta_{i}^{\max }(k-1)-\theta_{i}\right.$,

$$
\left.\hat{\theta}_{i}(k)-\theta_{i}+\|\hat{\theta}(k)-\theta\|_{\infty}\right] \geq 0
$$

またアルゴリズム 1 の仮定により $\theta_{i}^{\max }(0)-\theta_{i} \geq 0$ で ある.よってすべての $k て ゙ \theta_{i}^{\max }(k) \geq \theta_{i}$ となる. 同様 に $\theta_{i}^{\min }(k) \leq \theta_{i}$ も示すことができる.
2. $\theta_{i}^{\max }(k)$ の定義により

$$
\begin{aligned}
& \theta_{i}^{\max }(k)-\theta_{i}^{\max }(k-1) \\
& \quad=\min \left[\theta_{i}^{\max }(k-1), \hat{\theta}(k)+\alpha(k)\right]-\theta_{i}^{\max }(k-1) \\
& \quad=\min \left[0, \hat{\theta}(k)+\alpha(k)-\theta_{i}^{\max }(k-1)\right] \leq 0
\end{aligned}
$$

よって $\theta_{i}^{\max }(k) \leq \theta_{i}^{\max }(k-1)$. 同様に $\theta_{i}^{\min }(k) \geq \theta_{i}^{\min }(k$ $-1)$.

3. 補題 1 より

$$
\lim _{k \rightarrow \infty} \alpha(k) \rightarrow 0, \quad \lim _{k \rightarrow \infty}\left\{\hat{\theta}_{i}(k)-\theta_{i}\right\} \rightarrow 0
$$

となるので

$$
\begin{aligned}
& \lim _{k \rightarrow \infty}\left\{\theta_{i}^{\max }(k)-\theta_{i}\right\} \\
& =\lim _{k \rightarrow \infty} \min \left[\theta_{i}^{\max }(k-1)-\theta_{i}, 0\right]=0 \\
& \lim _{k \rightarrow \infty}\left\{\theta_{i}^{\min }(k)-\theta_{i}\right\} \\
& =\lim _{k \rightarrow \infty} \max \left[\theta_{i}^{\min }(k-1)-\theta_{i}, 0\right]=0
\end{aligned}
$$

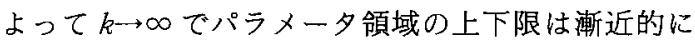
真值へと近づく。\|

3.2 連続時間系 次の連続時間システムを考える ( $s$ は微行演算子).

$$
y(t)=\frac{b_{1} s^{n-1}+\cdots+b_{n}}{s^{n}+a_{1} s^{n-1}+\cdots+a_{n}} u(t)
$$

安定多項式 $H(s)=s^{n}+h_{1} s^{n-1}+\cdots+h_{n}\left(h_{1}, \cdots, h_{n}\right.$ は 既知を用いて上式を

$$
f_{y 0}(t)=\sum_{i=1}^{n}\left(-a_{i} f_{y i}(t)+b_{i} f_{u i}(t)\right)=\zeta^{\mathrm{T}}(t) \theta
$$

のように書き改める。ただし

$$
\begin{aligned}
& f_{y i}(t)=\frac{s^{n-i}}{H(s)} y(t) \quad(i=0,1, \cdots, n) \\
& f_{u i}(t)=\frac{s^{n-i}}{H(s)} u(t) \quad(i=1,2, \cdots, n) \\
& \theta=\left[\begin{array}{llllll}
a_{1} & \cdots & a_{n} & b_{1} & \cdots & b_{n}
\end{array}\right]^{\mathrm{T}} \\
& \zeta(t)=\left[\begin{array}{lll}
-f_{y 1} \cdots-f_{y n} & f_{u 1} \cdots f_{u n}
\end{array}\right]^{\mathrm{T}}
\end{aligned}
$$

(12)式で表現されるプラントに対して同定モデルを

$$
\begin{aligned}
& \hat{f}_{y 0}(t)=\zeta^{\mathrm{T}}(t) \hat{\theta}(t) \\
& \hat{\theta}(t)=\left[\begin{array}{ll}
\bar{a}_{1}(t) \cdots \bar{a}_{n}(t) & \hat{b}_{1}(t) \cdots \bar{b}_{n}(t)
\end{array}\right]^{\mathrm{T}}
\end{aligned}
$$

と定義すると，次の誤差方程式が得られる.

$$
\begin{aligned}
& e(t)=\vec{f}_{y 0}(t)-f_{y 0}(t)=\zeta(t)^{\mathrm{T}} \psi(t) \\
& \psi(t)=\hat{\theta}(t)-\theta
\end{aligned}
$$

連続時間でのパラメー夕存在領域縮小アルゴリズム の基本的な概念は離散時間系と同一であり, 逐次式が 微分方程式で，和が時間積分で与えられる。

\section{《アルゴリズム $2>$}

1. 離散時間同様 $\left[\theta_{i}^{\min }(0), \theta_{i}^{\max }(0)\right](i=1,2, \cdots, 2 n)$ を評価する。

2. $\gamma=\frac{1}{2} \max _{i}\left(\theta_{i}^{\max }(0)-\theta_{i}^{\min (0))}(i=1,2, \cdots, 2 n)\right.$ と $お く$.

3. 次の最小二乗形同定則を用いて $\theta$ の推定值 
$\hat{\theta}(t)$ を計算する.

$$
\begin{aligned}
& \dot{\hat{\theta}}(t)=-\lambda_{2}(t) \Gamma(t) \zeta(t) e(t) \\
& \dot{\Gamma}(t)=\lambda_{1}(t) \Gamma(t)-\lambda_{2}(t) \Gamma(t) \zeta(t) \zeta^{\mathrm{T}}(t) \Gamma(t) \\
& \Gamma(0)>0
\end{aligned}
$$

4. $\alpha(t)=\exp \left(-\int_{0}^{t} \lambda_{1}(\tau) \mathrm{d} \tau\right)\left\|\Gamma(t) \Gamma^{-1}(0)\right\|_{\infty} \gamma$ を計

算する。

5. 時刻 $t$ での $\theta_{i}$ の存在領域が

$$
\begin{aligned}
\theta_{i}^{\operatorname{mn}}(t) & =\max _{0 \leq r \leq t}\left[\hat{\theta}_{i}(\tau)-\alpha(\tau)\right] \\
\theta_{i}^{\max }(t) & =\min _{0 \leq \tau \leq t}\left[\hat{\theta}_{i}(\tau)+\alpha(\tau)\right] \\
(i & =1,2, \cdots, 2 n)
\end{aligned}
$$

で与えられる。

連続時間系に対しても次の定理が成立する。

[定理 2] アルゴリズム 2 で得られる $\theta_{i}^{\mathrm{min}}(t)$, $\theta_{i}^{\max }(t)(i=1, \cdots, 2 n)$ は以下の関係を満たす。

1. $\theta_{i}^{\min }(t) \leq \theta_{i} \leq \theta_{i}^{\max }(t) \quad \forall t$

2. $\quad \dot{\theta}_{i}^{\min }(t) \geq 0 \quad \forall t, \quad \dot{\theta}_{i}^{\max }(t) \leq 0 \quad \forall t$

3. ベクトル $\zeta(t)$ が PE 条件を満たし、, $\|\Gamma(t)\|_{\infty}$ が 有界ならば, $\theta_{i}^{\min }(t), \theta_{i}^{\max }(t)$ は真値 $\theta_{i}$ に収束する。

次の補題は補題 1 に対応するものである5).

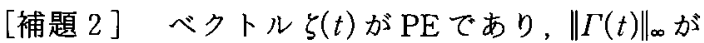
有界ならば， $\psi(t)=\hat{\theta}(t)-\theta$ に対して

$$
\|\psi(t)\|_{\infty} \leq \exp \left(-\int_{0}^{t} \lambda_{1}(\tau) \mathrm{d} \tau\right)\left\|\Gamma(t) \Gamma^{-1}(0)\right\|_{\infty} \gamma
$$

がすべての時刻 $t$ で成り立つ。

(補題 2 の証明)

$$
\dot{\Gamma}(t) \Gamma^{-1}(t)+\Gamma(t) \dot{\Gamma}^{-1}(t)=\frac{\mathrm{d}}{\mathrm{d} t}(I)=0
$$

であるから，(16)式を代入して

$$
\dot{\Gamma}^{-1}(t)=-\lambda_{1}(t) \Gamma^{-1}(t)+\lambda_{2}(t) \zeta(t) \zeta^{\mathrm{T}}(t)
$$

(15)，(18)式より

$$
\begin{aligned}
\frac{\mathrm{d}}{\mathrm{d} t}\left[\Gamma^{-1}(t) \psi(t)\right] & =\dot{\Gamma}^{-1}(t) \phi(t)+\Gamma^{-1}(t) \dot{\psi}(t) \\
& =-\lambda_{1}(t) \Gamma^{-1}(t) \psi(t)
\end{aligned}
$$

となるので

$$
\begin{aligned}
& \Gamma^{-1}(t) \phi(t) \\
& \quad=\exp \left(-\int_{0}^{t} \lambda_{1}(\tau) \mathrm{d} \tau\right) \Gamma^{-1}(0) \psi(0)\|\psi(t)\|_{\infty} \\
& \quad \leq \exp \left(-\int_{0}^{t} \lambda_{1}(\tau) \mathrm{d} \tau\right)\left\|\Gamma(t) \Gamma^{-1}(0)\right\|_{\infty}\|\phi(0)\|_{\infty} \\
& \quad \leq \exp \left(-\int_{0}^{t} \lambda_{1}(\tau) \mathrm{d} \tau\right)\left\|\Gamma(t) \Gamma^{-1}(0)\right\|_{\infty} \gamma \quad \|
\end{aligned}
$$

(定理 2 の証明)

$$
\begin{aligned}
& \text { 1. } \quad \theta_{i}^{\max }(t) \text { の定義により } \\
& \theta_{i}^{\max }(t)-\theta_{i} \\
&=\min _{0 \leq \tau \leq t}\left[\hat{\theta}_{i}(\tau)+\alpha(\tau)\right]-\theta_{i} \\
&=\min _{0 \leq \tau \leq t}\left[\hat{\theta}_{i}(\tau)-\theta_{i}+\alpha(\tau)\right]
\end{aligned}
$$

$$
\geq \min _{0 \leq \tau \leq t}\left[\hat{\theta}_{i}(\tau)-\theta_{i}+\left\|\hat{\theta}_{i}(\tau)-\theta_{i}\right\|_{\infty}\right] \geq 0
$$

よって $\theta_{i}^{\max }(t) \geq \theta_{i}$. 同様に $\theta_{i}^{\min }(t) \leq \theta_{i}$.

2. アルゴリズム 2 の 5.より明らか.

3 . 補題 2 上り

$$
\lim _{t \rightarrow \infty} \alpha(t) \rightarrow 0, \quad \lim _{t \rightarrow \infty}\left\{\hat{\theta}_{i}(t)-\theta_{i}\right\} \rightarrow 0
$$

であるから

$$
\begin{aligned}
& \lim _{t \rightarrow \infty}\left\{\theta_{i}^{\max }(t)-\theta_{i}\right\}=\min _{0 \leq \tau \leq t}\left\{\hat{\theta}_{i}(\tau)-\theta_{i}\right\}=0 \\
& \lim _{t \rightarrow \infty}\left\{\theta_{i}^{\min }(t)-\theta_{i}\right\}=\max _{0 \leq \tau \leq t}\left\{\hat{\theta}_{i}(\tau)-\theta_{i}\right\}=0
\end{aligned}
$$

となる.よってパラメー夕領域の上下限は漸近的に真 值へと近づく

\section{4. 二次安定化適応制御}

前述の同定法の特徵は, 各時刻で真值の存在領域が

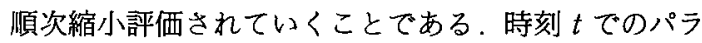
メータの同定值として

$$
\hat{\theta}_{i}(t)=\frac{1}{2}\left(\theta_{i}^{\min }(t)+\theta_{i}^{\max }(t)\right)
$$

を採用すると，各時間で同定值，及び真值と同定値の 「ずれ」が評価される。つまり，パラメータ領域その ものが推定誤差の大きさの範囲を与える。この考えを 用いれば，状態空間行列がある推定された行列とその 不確かさを表す行列の和として書かれ，しかもその不 確かさを示す行列の「大きさ」が与えられた場合に， システムを安定化する制御入力を求める問題として適 応制御問題をとらえ直すことができる。

このような問題を最近のロバスト制御理論は二次安 定化問題と呼んでいる.すなわち，次のような構造的 不確かさを持つ系

$$
\dot{x}=(A(t)+\Delta A(t)) x(t)+(B(t)+\Delta B(t)) u(t)
$$

$\|\Delta A\|, \quad\|\Delta B\|$ known

に対し，ある時間でのパラメータ領域縮小アルゴリズ ムによって評価されるプラントの存在領域全てを安定 化する問題と捉えることができる。このコントローラ の存在は, 二次安定化理論によるリカッチ方程式によ って判定される。

[二次安定化 ] ${ }^{6,7)}$ システムとその誤差が

$$
\begin{aligned}
& \dot{x}=(A+\Delta A(t)) x(t)+(B+\Delta B(t)) u(t) \\
& {[\Delta A(t) \quad \Delta B(t)]=D F(t)\left[\begin{array}{ll}
E_{1} & E_{2}
\end{array}\right]} \\
& \|F(t)\|<1
\end{aligned}
$$

と与えられるとき，行列 $E_{2}$ の特異值分解

によって

$$
E_{2}=\left[\begin{array}{ll}
U_{1} & U_{2}
\end{array}\right]\left[\begin{array}{cc}
J_{2} & 0 \\
0 & 0
\end{array}\right]\left[\begin{array}{l}
V_{1}^{\mathrm{T}} \\
V_{2}^{\mathrm{T}}
\end{array}\right]
$$

$$
\Phi=V_{2}^{\mathrm{T}}, \quad \Xi=V_{1} J_{2}{ }^{-2} V_{1}^{\mathrm{T}}
$$

を定義する.ここでの, $\Xi$ は誤差の大きさの情報を持 
つた行列である。

この時, 線形制御でシステムを二次安定化すること ができる必要十分条件は, 次のリカッチ方程式が適当 な正数 $\varepsilon$ に対して正定解 $P$ を持つことである.

$$
\left(A-B \Xi E_{2}^{\mathrm{T}} E_{1}\right)^{\mathrm{T}} P+P\left(A-B \Xi E_{2}^{\mathrm{T}} E_{1}\right)
$$

$$
\begin{aligned}
& +P D D^{\mathrm{T}} P-P B \Xi B^{\mathrm{T}} P-\frac{1}{\varepsilon} P B \Phi^{\mathrm{T}} \Phi B^{\mathrm{T}} P \\
& +E_{1}^{\mathrm{T}}\left(I-E_{2} \Xi E_{2}^{\mathrm{T}}\right) E_{1}+\varepsilon Q=0
\end{aligned}
$$

また線形二次安定化制御のひとつはこの行列 $P$ を用 いて

$$
u(t)=-\left\{\left(\frac{1}{2 \varepsilon} \Phi^{\mathrm{T}} \Phi+\Xi\right) B^{\mathrm{T}} P+\Xi E_{2}^{\mathrm{T}} E_{1}\right\} x(t)
$$

と与えられる。

当然のことではあるが，\|AA\|,\|AB\|が大きすぎれ ばリカッチ方程式は正定解を持たず，二次安定化理論 では何の安定化解も得られない。このため次のような 手順が必要となる。

\section{《アルゴリズム $3 \gg$}

1. 初期値としてパラメータの存在範囲を見積も る。ただし評価不可能な場合には大きめに見積もって おく.

2. あまり大きくない $\mathrm{PE} な$ 外部入力でシステムを 励起し，2節で述べたパラメータの存在領域を計算す る.

3. ステップ 2 と並行して (23) 式のリカッチ方程式 が正定解を持つかどうか判断する.

4. 正定解が得られるまでステップ $2 ， 3$ を繰り返
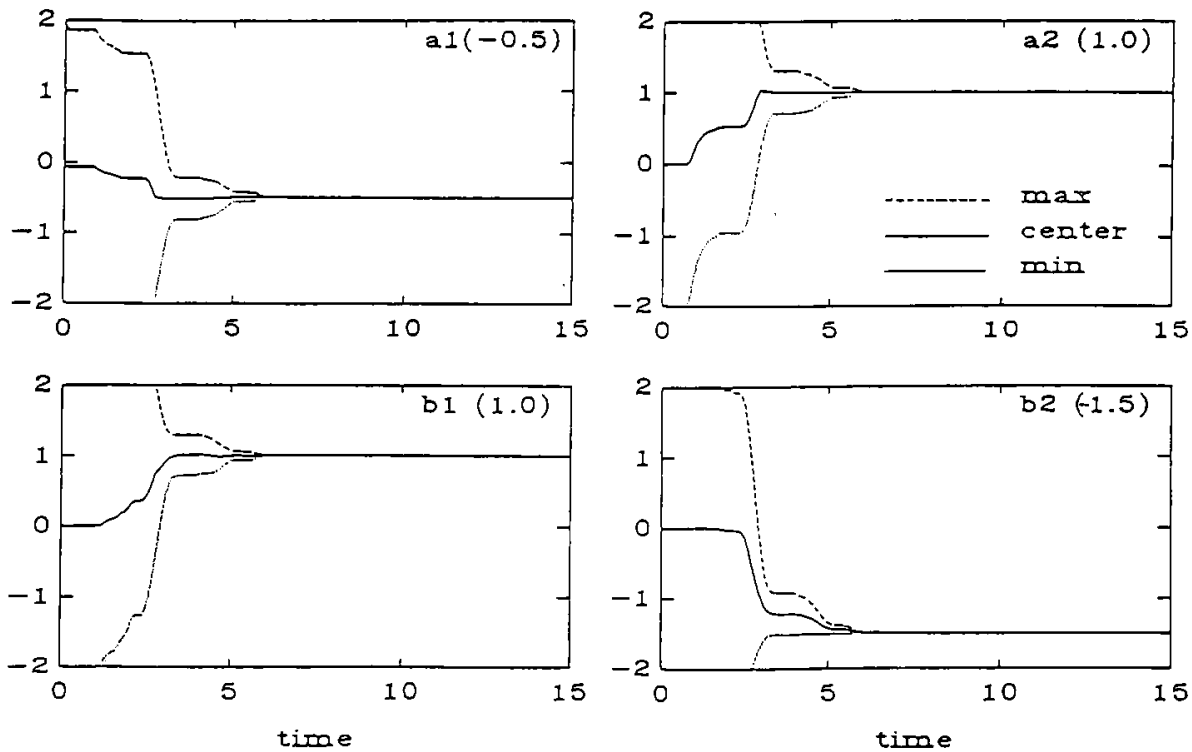

第 1 図 システム 1 のパラメータ領域の時間変化
し, 得られたならば以下のような式で制御入力を発生 する。

$$
\begin{aligned}
& u(t)=u_{i}(t)+u_{c}(t) \\
& u_{i}(t)=\text { 適当な励起入力 }(\sin \text { 波など }) \\
& u_{\mathrm{c}}(t)=\mathrm{Eq} .(24)
\end{aligned}
$$

上記のアルゴリズムにより構成される制御系を適応二 次安定化制御系と呼ぶ。この有効性を, 簡単な数值例 によって検証する。

[システム 1] 不安定かつ非最小位相

・システム

$$
y(t)=\frac{b_{1} s+b_{2}}{s^{2}+a_{1} s+a_{2}} u(t)=\frac{s-1.5}{s^{2}-0.5 s+1} u(t)
$$

・未知パラメータベクトルの初期推定存在領域

$$
\theta^{\max }(0)=[2,2,2,2]^{\mathrm{T}}
$$$$
\theta^{\min }(0)=\left[\begin{array}{llll}
-2, & -2,-2,-2
\end{array}\right]^{\mathrm{T}}
$$

- 同定入力

$$
u_{i}(t)=0.2 \sin (\pi t)+0.2 \sin (0.1 \pi t)
$$

・サンプリングタイム：0.1秒

系は極 $0.25 \pm 0.97 i$ を持つ不安定系であり，パラメ 一夕同定の初期值が全て零であるために，この段階で は当然何等の安定化情報も得られない，また初期の パラメー夕誤差の大きさも真值の大きさに対して 200 50\%程度あり, 二次安定化解が存在しないこと は直感的にも明らかである。

第 1 図はシステム 1 のパラメータ領域の変化である が、すべてのパラメータにおいて定理 1 の性質が成立 しており，収束性も良好である，第 2 図は入出力の変 化である．系は不安定であるので同定入力に対して変 
動するが，入力が小さいので，その挙動はほほ入力を 加えてない場合に相当する．6秒ほどで正定解が得ら れた後は同定入力は零とし，二次安定化制御入力によ
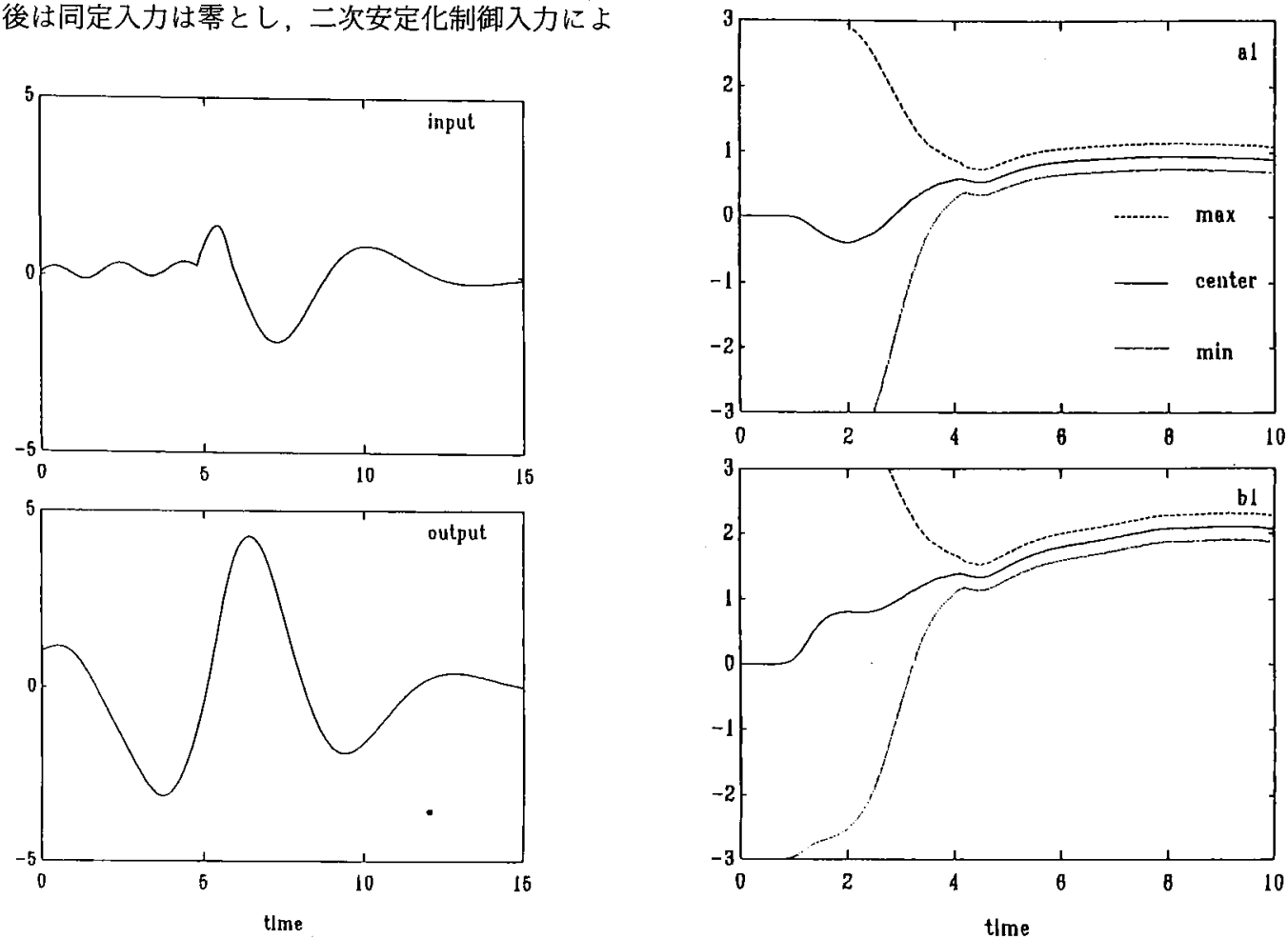

第 2 図 システム 1 の入出力の時間変化

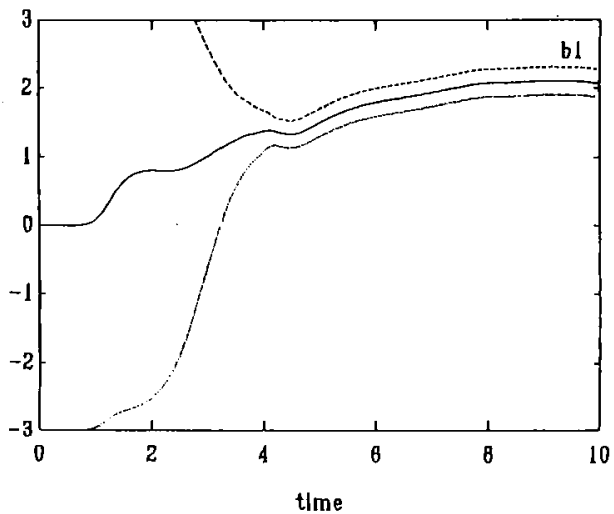

第 3 図 システム 2 のパラメー夕領域の時間変化

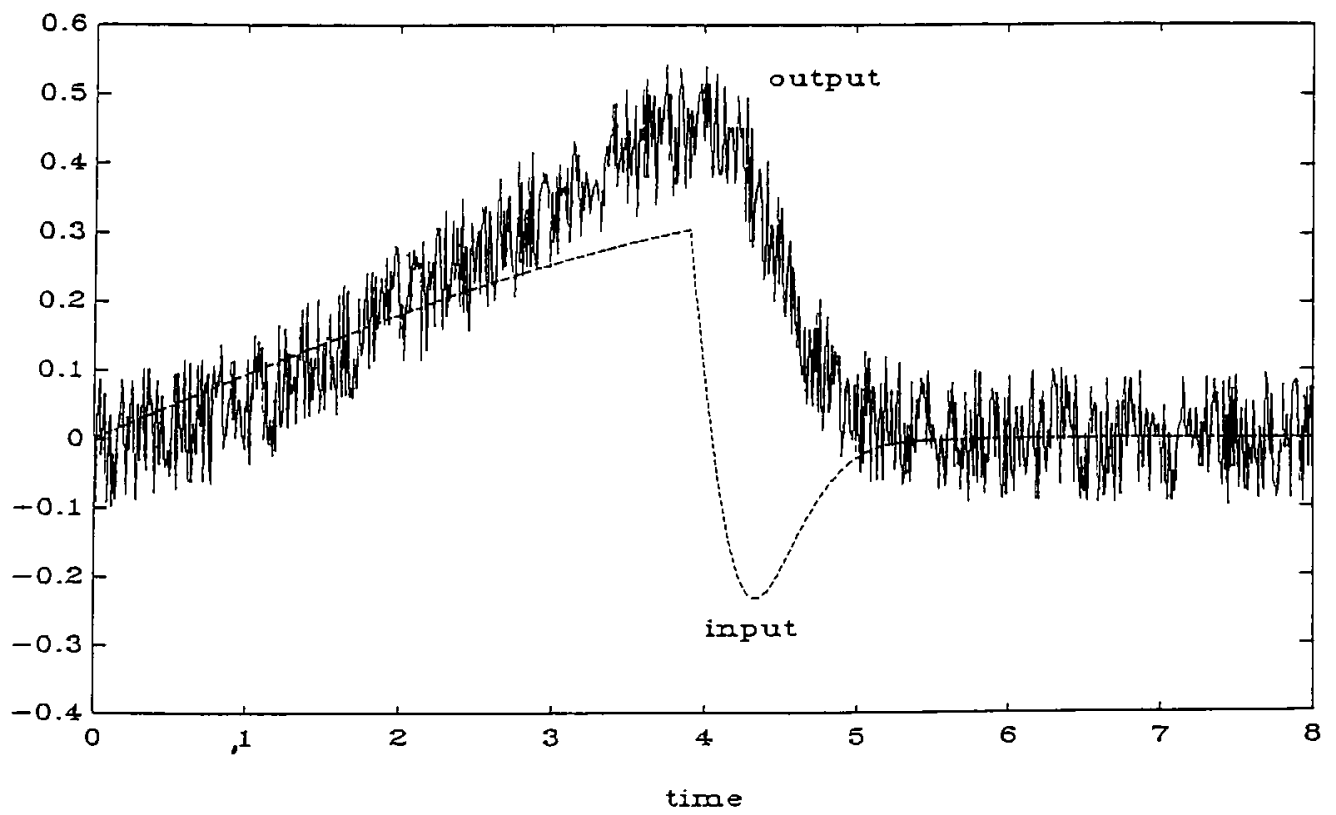

第 4 図 システム 2 の入出力の時間変化 
ってすみやかに出力が安定化されている。

[システム 2] 低次近似モデルかつ観測雑音下

\section{・システムと観測值}

$$
\begin{aligned}
& y(t)=\frac{2}{s+1} \frac{229}{s^{2}+30 s+229} u(t) \\
& y_{d}(t)=y(t)+0.1 \times \text { rand } \\
& \quad \text { rand は大きさ } 1 \text { 以下のランダム信号 } \\
& \text { ・システムの低次近似モデル }
\end{aligned}
$$

$$
y(t)=\frac{b_{1}}{s+a_{1}} u(t)
$$

・パラメータの初期推定存在領域

$$
\theta^{\max }(0)=[3,3]^{\mathrm{T}}
$$$$
\theta^{\mathrm{mln}}(0)=[-3,-3]^{\mathrm{T}}
$$

- 同定入力

$$
u_{i}(t)=\sin (0.5 \pi t)
$$

・サンプリングタイム：0.01 秒

システムは 3 次系であるが，その 1 次の近似モデル を考え，それにアルゴリズムを適用し，系全体の安定 化を図る. 観測雑音の大きさは近似システムのパラメ 一夕真值の大きさに対して 5〜10\%程度のものを考元 た。

多項式 $H(s)=s^{2}+1.2 s+1$ で表わされるローパスフ イルタを通過させた入出力信号を用いたパラメータ領 域縮小アルゴリズムによって，パラメータは収束し (第 3 図)，プラントも安定化されている(第 4 図).し かし低近似モデルではパラメータの真值は存在しない ため, 推定值 $a_{1}, b_{1}$ に幅を持たせてある．このような 低次近似モデルで，さらに観測雑音も含まれるより実 際に近い場合においてもほほ正しい推定值が得られ， プラントの制御も良好である。

\section{5. 航空機に対する応用例}

高性能航空機のピッチ姿勢制御系設計に本手法を 適用する。対象機体はF-4Cで, 飛行状態は高度 $10,668 \mathrm{~m}(35,000 \mathrm{ft}) ， マ ッ 八$ 数 0.60 , 速度 $178 \mathrm{~m} / \mathrm{s}$ $(584 \mathrm{ft} / \mathrm{s})$, 釣合い迎角 $9.4 \mathrm{deg}$ の水平飛行である ${ }^{8}$. 対象システムの状態方程式表現は

$$
\begin{aligned}
& \frac{\mathrm{d}}{\mathrm{d} t}\left[\begin{array}{l}
\dot{\theta} \\
\alpha \\
\eta
\end{array}\right]=\left[\begin{array}{ccc}
a_{11} & a_{12} & b_{1} \\
a_{21} & a_{22} & b_{2} \\
0 & 0 & -20
\end{array}\right]\left[\begin{array}{l}
\dot{\theta} \\
\alpha \\
\eta
\end{array}\right]+\left[\begin{array}{c}
0 \\
0 \\
20
\end{array}\right] \eta_{\mathrm{c}} \\
& n_{z}=\left[\begin{array}{lll}
c_{1} & c_{2} & c_{3}
\end{array}\right]\left[\begin{array}{c}
\dot{\theta} \\
\alpha \\
\eta
\end{array}\right]
\end{aligned}
$$

て，伝達関数が

$$
n_{z}=\frac{\beta_{1} s^{2}+\beta_{2} s+\beta_{3}}{s^{3}+\alpha_{1} s^{2}+\alpha_{2} s+\alpha_{3}} \eta_{\mathrm{c}}
$$

と表わされる 3 次の安定系を考える．ただしここで，

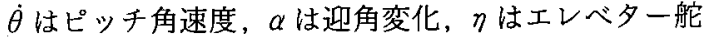
角変化， $\eta_{\mathrm{c}}$ はエレベタ一舵角制御入力， $n_{z}$ は機体重 心での垂直加速度を示す。

未知パラメータベクトルの初期推定存在領域, 及び 初期推定値は

$$
\begin{aligned}
& \theta^{\max }(0)=\left[\begin{array}{lllll}
70, & 70, & 80, & 70, & 30,-480
\end{array}\right]^{\mathrm{T}}
\end{aligned}
$$

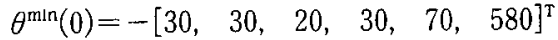

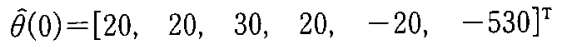

と選択した．入力として $u=$ Eq. (25)を用い，励起入 力は周期 1 秒，大きさ 0.5 [in] の矩形波とする.フ イルターの安定多項式は $H(s)=s^{3}+6 s^{2}+11 s+6$ とし た。システムは連続時間系を考えたが，その観測時間 間隔は $1 / 30$ 秒(約 0.03 秒) と仮定した.

第 5 図は各々パラメータ領域及び推定值の変化の様 子の一例を係数 $b_{i}$ について示したものである.ここ では, 入力が制御入力のみになった時はパラメータ領 域が十分小さくなったと評価し，それ以上の領域の縮 小は行っていない，第 6 図は入出力変化の様子を表わ している。
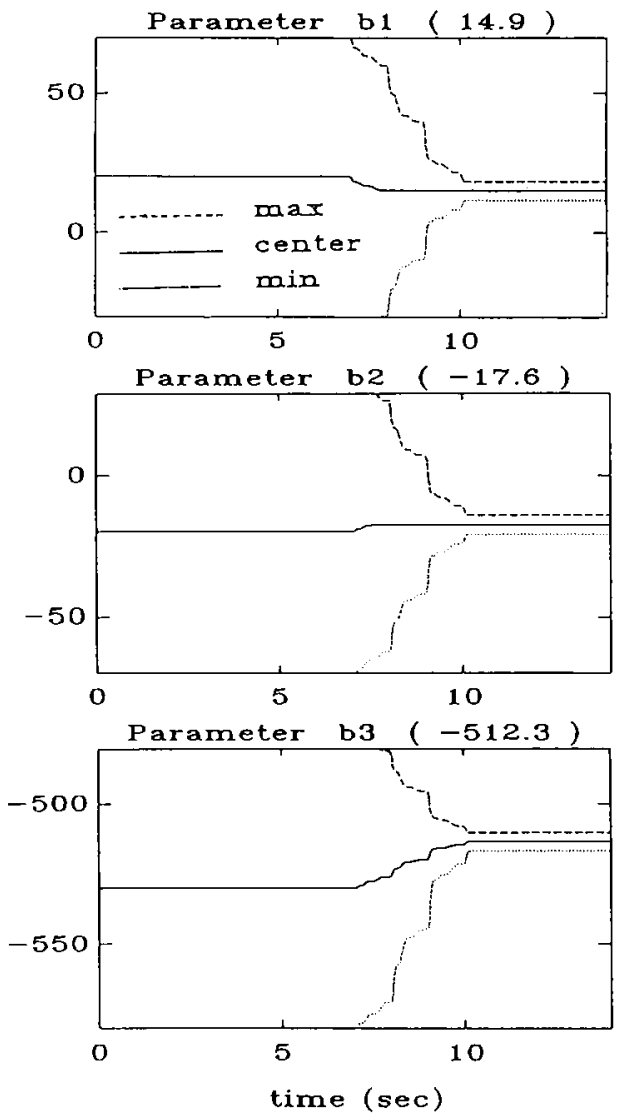

第 5 図 パラメータ領域の時間変化 

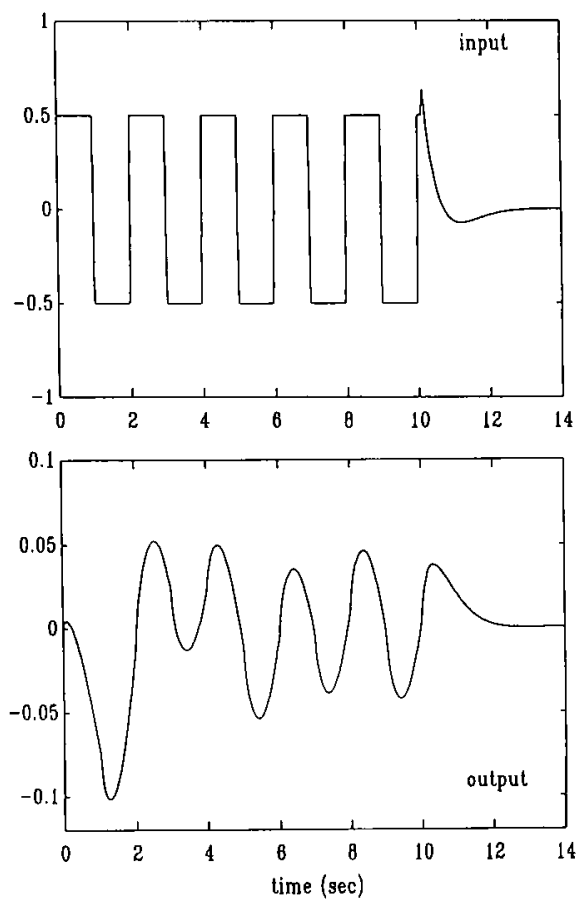

第6図 入出力の時間変化

パラメータが一定值のこの場合は，単調性，収束 性，収束速度に扔いてほ济满できる結果が得られ た．しかし，同定すべきパラメータのうち，大きさが 極端に異なっているものがあると, システム全体の同 定及び制御の精度が悪くなることがある。これは，規 格化して初期パラメータ推定存在領域を選ぶことによ りほほ解決できる。 また，同定入力の周期を小さくし たり，又は入力の振幅を大きくするとより速く収束す るが，実際の航空機では，実現の可能性が問題となろ う。
6. ま と

適応制御系の実用上重要な問題点である過渡状態で の特性改善を目的とし, 新しい適応制御系の構成法を 示した。.まず各時刻での同定值が真值に対してどれく らい良好なものであるかを評価するため，パラメータ の存在領域を導入し，その計算アルゴリズムを，離散 系と連続系に対し構成した. 未知パラメータの存在領 域を求めることにより，プラントの特性をある中心值 とその周りの誤差としてとらえることができ, 最近の ロバスト制御理論の利用が可能となる。一例として二 次安定化理論を使った適応二次安定化制御系を提案 し，その有効性を幾つかの数值例を用いて検討した。

\section{参 考 文 献}

1) Miller, D. E. and Davison, E. J.: An Adaptive Controller Which Provides an Arbitrarily Good Transient and Steady-State Response, IEEE Trans. Automatic Control, AC-36 (1991), pp. 68-81.

2) Samson, C.: An Adaptive LQ Controller for Non-Minimum Phase System, Int. J. Control, 35 (1982), pp. 1-28.

3) Kreisselmeier, G.: An Approach to Stable Indirect Adaptive Control, Automatica, 21 (1985), pp. 425-431.

4) 田村捷利, 菊川 暁, 尾形麿次: オーバーシュートを生じさ せないMRACSの一構成，計測自動制御学会論文集，25 (1989), pp. 558-565.

5）新中新二：適応アルゴリズム, 産業図書, 東京, 1990.

6) Xie, L. and Souza, C. E. : Robust $H^{\infty}$ Control for Linear Time-Invariant Systems with Norm-Bounded Uncertainty in the Input Matrix, Systems Control Lett., 14 (1990), pp. 389-396.

7) 藤井隆雄：2次安定化とロバスト制御，計測と制御， 29 (1990), pp. 142-150.

8) Heffley, R. K. and Jewell, W. F. : Aircraft Handling Qualities Data, NASA CR-2144, 1972.

9) Sastry, S. and Bodson, M. : Adaptive Control-Stability, Convergence, and Robustness, Rrentice-Hall, New Jersey, 1989 . 